\title{
Phase Velocity Spectrum Analysis for A Time Delay Comb Transducer for Guided Wave Mode Excitation
}

\author{
M. J. Quarry, J. L. Rose
}

This article was submitted to $28^{\text {th }}$ Annual Review of Progress in Quantitative Nondestructive Evaluation, Brunswick, ME., July 29-August 3, 2001

U.S. Department of Energy

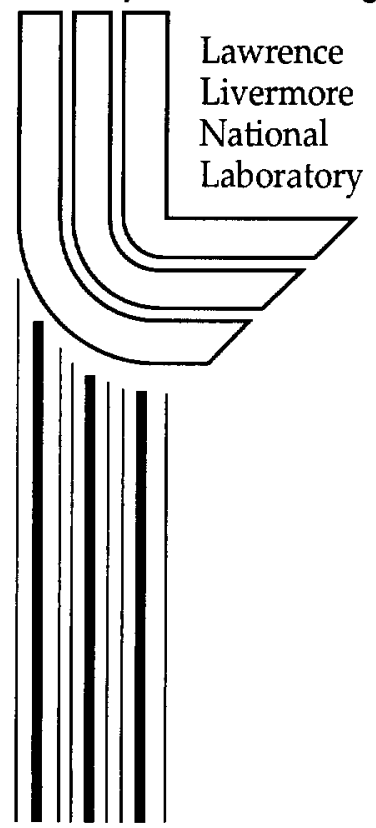

September 26, 2000 


\section{DISCLAIMER}

This document was prepared as an account of work sponsored by an agency of the United States Government. Neither the United States Government nor the University of California nor any of their employees, makes any warranty, express or implied, or assumes any legal liability or responsibility for the accuracy, completeness, or usefulness of any information, apparatus, product, or process disclosed, or represents that its use would not infringe privately owned rights. Reference herein to any specific commercial product, process, or service by trade name, trademark, manufacturer, or otherwise, does not necessarily constitute or imply its endorsement, recommendation, or favoring by the United States Government or the University of California. The views and opinions of authors expressed herein do not necessarily state or reflect those of the United States Government or the University of California, and shall not be used for advertising or product endorsement purposes.

This is a preprint of a paper intended for publication in a journal or proceedings. Since changes may be made before publication, this preprint is made available with the understanding that it will not be cited or reproduced without the permission of the author.

This work was performed under the auspices of the United States Department of Energy by the University of California, Lawrence Livermore National Laboratory under contract No. W-7405-Eng-48.

This report has been reproduced directly from the best available copy.

Available electronically at http://www.doc.gov/bridge

Available for a processing fee to U.S. Department of Energy

And its contractors in paper from

U.S. Department of Energy

Office of Scientific and Technical Information

$$
\text { P.O. Box } 62
$$

Oak Ridge, TN 37831-0062

Telephone: (865) 576-8401

Facsimile: (865) 576-5728

E-mail: reports@adonis.osti.gov

Available for the sale to the public from

U.S. Department of Commerce

National Technical Information Service 5285 Port Royal Road Springfield, VA 22161

Telephone: (800) 553-6847

Facsimile: (703) 605-6900

E-mail: orders@ntis.fedworld.gov

Online ordering: http://www.ntis.gov/ordering.htm

\section{OR}

Lawrence Livermore National Laboratory

Technical Information Department's Digital Library

http://www.llnl.gov/tid/Library.html 


\title{
PHASE VELOCITY SPECTRUM ANALYSIS FOR A TIME DELAY COMB TRANSDUCER FOR GUIDED WAVE MODE EXCITATION
}

\author{
M.J. Quarry' and J.L. Rose ${ }^{2}$ \\ ${ }^{1}$ Lawrence Livermore National Laboratory, 7000 East Ave., Livermore, CA 94550 \\ ${ }^{2}$ The Pennsylvania State University, 212 Earth and Engineering Sciences Building, University \\ Park, PA 16802
}

\begin{abstract}
A theoretical model for the analysis of ultrasonic guided wave mode excitation of a comb transducer with time delay features was developed. Time delay characteristics are included via a Fourier transform into the frequency domain. The phase velocity spectrum can be used to determine the mode excitation on the phase velocity dispersion curves for a given structure. Experimental and theoretical results demonstrate the tuning of guided wave modes using a time delay comb transducer.
\end{abstract}

\section{BACKGROUND}

An important issue in the development of guided waves is the generation and control of modes. Guided wave techniques have been developed for various applications involving pipes, tubes, and plates. Some recent studies in piping applications include [1], [2], [3]. Ditri [4] showed that different guided wave modes behave differently in a given structure. One mode at a certain frequency may detect a flaw, while the same mode at a different frequency may fail to yield an indication. Flaws often have peak responses for a mode and frequency that is typically unknown. Numerical scattering has been researched in [5], [6], and [7], but numerical studies assume an exact geometry with a defined orientation of a flaw. However, real world defects can have unknown geometries and orientations. An approach to find peak responses from flaws is to perform mode tuning. Mode tuning is an experimental approach to find a mode and frequency with characteristics that are desirable for a given inspection goal, such as defect sensitivity, penetration power, or sizing information. One method could be sweep a variable angle wedge through the incident angle. Shin [8] demonstrated mode tuning benefits for flexural modes in steam generator tubes. Another potential method is to use a comb transducer and develop a variable spacing mechanism. A drawback is that these methods require mechanical sweeping. An alternative is to use a comb transducer with time delay characteristics. This method enables the tuning to be performed electronically. 
A method for determining the wave excitation of a given source distribution based on the complex reciprocity relation is given in Auld [9]. Auld [10] used the method to analyze the excitation of surface waves by expanding the fields in a normal mode expansion. Ditri [11] utilized the method for determining the excitation of guided waves in a hollow cylinder by an arbitrary loading distribution. An alternative method to analyzing the excitation is to use an integral transform to solve the boundary value problem of a source loading as done by Viktorov [12] and Pelts [13]. The advantage to the normal mode expansion approach is that the amplitude of a given mode is solved for directly in terms of the loading parameters. As a result more physical insight can be obtained.

\section{THEORY}

Ditri [11] produced a solution for the excited amplitude of a given mode due to an arbitrary loading distribution on the surface. Ditri assumed a time harmonic solution. Ditri's solution can be extended to include time delay parameters by performing a Fourier transform on the time variable.

An orthogonality relation for the waveguide modes of a traction free cylinder must be established for the application of normal mode expansion theory. A derivation is given in [11]. Orthogonality enables the fields in the waveguide to be expanded into an infinite series of the normal modes of the hollow cylinder.

The solution begins with the complex reciprocity relation, which is given by

$$
\nabla \cdot\left(\vec{v}_{1} \cdot T_{2}^{*}+\vec{v}_{2}^{*} \cdot T_{1}\right)=0
$$

where $\mathrm{v}$ and $\mathrm{T}$ are the velocity and stress fields, and " 1 " and " 2 " subscripts denote two different solutions to elastodynamic field equations governing the propagation of elastic waves in a homogeneous, isotropic, linear media. Assume a harmonic time dependence of the form $\mathrm{e}^{\mathrm{j} \omega \mathrm{t}}$, where $\omega$ is the circular frequency. The asterisk represents complex conjugation. The fields may be represented by a normal mode summation over all possible modes given by

$$
\begin{aligned}
& \vec{v}_{1}=\sum_{m} A_{m}(z) \vec{v}_{m}(r, \theta) \\
& T_{1}=\sum_{m} A_{m}(z) T_{m}(r, \theta),
\end{aligned}
$$

where $\mathrm{v}$ is the velocity vector, $\mathrm{T}$ is the stress tensor, $\mathrm{A}$ is the amplitude, and $\mathrm{m}$ is the mode number. Possible modes include the axisymmetric longitudinal and torsional modes as well as the nonaxisymmetric flexural modes. Axisymmetric loading eliminates any flexural modes from being generated as a result of orthogonality. Also, evanescent modes are ignored because of their rapid decay. The solutions with the subscript " 1 " denote the fields in the hollow cylinder due to the applied loading. The solutions with the subscript " 2 " may be represented by a mode $n$ as 


$$
\begin{aligned}
& \vec{v}_{2}=\vec{v}_{n}(r, \theta) e^{-j k_{n} z} \\
& T_{2}=T_{n}(r, \theta) e^{-j k_{n} z},
\end{aligned}
$$

where $k_{n}$ is the wave number of the nth mode. Applying these representations to Eq. (1) and integrating over the cross section of the hollow cylinder, plus substituting traction free boundary conditions yields

$$
4 P_{n n}\left(\frac{d}{d z}+j k_{n}\right) A_{n}(z)=\oint_{\partial S}\left(\vec{v}_{n}^{*} \cdot T_{n}\right) \cdot \hat{n} d S
$$

where $\mathrm{S}$ is the cross section of the cylinder and $\mathrm{P}_{\mathrm{n} n}$ is the power carried by the nth mode. Eq. (4) is linear ordinary differential equation that can be easily solved to produce

$$
A_{n}(z)=\frac{e^{-j k_{n} z}}{4 P_{n n}} \int_{c}^{z} e^{j k_{n} \eta}\left\{\oint_{\partial S} \vec{v}_{n}^{*} \cdot\left(T_{n} \cdot \hat{n}\right) d S\right\} d \eta,
$$

where the amplitude is assumed to be for the positive $\mathrm{z}$ forward propagating direction. A negative $\mathrm{z}$ backward propagating amplitude could be determined by changing the wave number to negative. The inner integral in Eq. (5) is function of $\mathrm{z}, \mathrm{f}(\mathrm{z})$, that is described by the loading distribution. The outer integral in Eq. (5), which is the integral over the loading length of the stress distribution, represents the phase velocity spectrum of the loading distribution. Phase velocity is obtained from the relation

$$
k_{n}=\frac{\omega}{V_{p h}}
$$

The intersection of the peaks of the frequency spectrum and the phase velocity spectrum on the dispersion curves is likely to be a mode that is generated with a dominant amplitude over any other possible modes. Analysis of the phase velocity spectrum is a valuable tool, because it can be used improve probe designs by tailoring the source parameters to optimize the excitation of particular modes.

\section{Phase Velocity Spectrum for a Time Delay Comb Transducer}

The effect of time delay parameters on the phase velocity spectrum of a comb transducer can be incorporated into the model by performing a Fourier transform on the time variable. Table 1 shows the general parameters of a comb transducer with time delay parameters. The time delay is td, $s$ is the spacing, $w$ is the element width, $L$ is the total length of comb, and $n$ is the number of elements. Uniform and width is assumed. Fig. 1 shows the coordinate system for a four element comb transducer on the surface of a hollow cylinder. A piston type loading is assumed for each element. The time excitation can be written in the

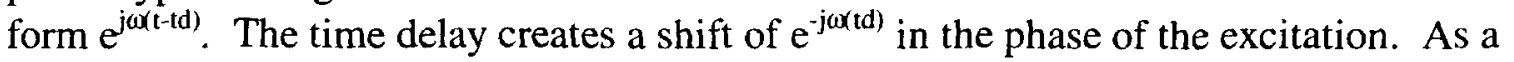


result, the phase velocity spectrum is altered. The phase shift changes the wave interference and shifts the peak of the phase velocity spectrum.

The phase velocity spectrum for a forward propagating direction can be written as

$$
G^{+}\left(V_{p h}\right)=\int_{-L / 2}^{w-L / 2} e^{j k_{m} z} d z+\int_{s-L / 2}^{s+w-L / 2} e^{j k_{m} z} e^{j \omega(t d)} d z+\int_{2 s-L / 2}^{2 s+w-L / 2} e^{j k_{m} z} e^{j 2 \omega(t d)} d z+\ldots \int_{(n-1) s-L / 2}^{(n-1) s+w-L / 2} e^{j k_{m} z} e^{j(n-1) \omega(t d)} d z
$$

Each integral in Eq. (7) represents an individual element in the array. The integral is zero in the gaps in between elements. Again, the relation in Eq. (6) is used to obtain a function of phase velocity. With a time delay equal to zero, the phase terms reduce to one, and the interference is governed by the spacing of the elements.

Table 1. General parameters for an n element comb transducer.

\begin{tabular}{|c|c|c|c|}
\hline Element No. & Starting Position & Ending Position & Time Delay \\
\hline 1 & $-\mathrm{L} / 2$ & $\mathrm{w}-\mathrm{L} / 2$ & 0 \\
\hline 2 & $\mathrm{~s}-\mathrm{L} / 2$ & $\mathrm{~s}+\mathrm{w}-\mathrm{L} / 2$ & $\mathrm{td}$ \\
\hline 3 & $2 \mathrm{~s}-\mathrm{L} / 2$ & $2 \mathrm{~s}+\mathrm{w}-\mathrm{L} / 2$ & $2 \mathrm{td}$ \\
\hline 4 & $3 \mathrm{~s}-\mathrm{L} / 2$ & $3 \mathrm{~s}+\mathrm{w}-\mathrm{L} / 2$ & $3 \mathrm{td}$ \\
\hline$\ldots$ & $\ldots$ & $\ldots$ & $\ldots$ \\
\hline $\mathrm{n}$ & $(\mathrm{n}-1) \mathrm{s}-\mathrm{L} / 2$ & $(\mathrm{n}-\mathrm{1}) \mathrm{s}+\mathrm{w}-\mathrm{L} / 2$ & $(\mathrm{n}-1) \mathrm{td}$ \\
\hline
\end{tabular}

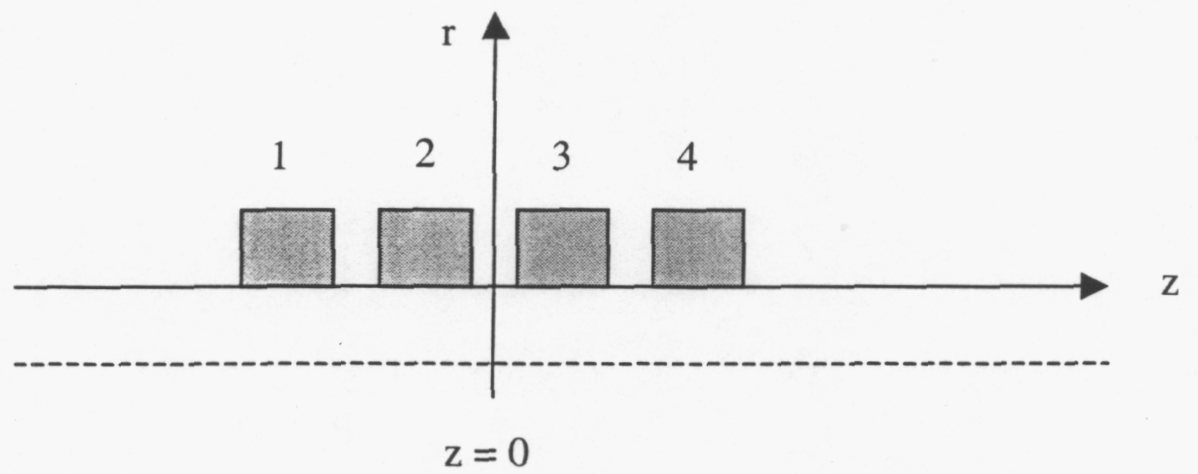

FIGURE 1. Coordinate system for a four element comb transducer.

The value of time delay for guided wave inspection is the ability to shift the excitation to another mode without having to change spacing. This can be done with time delay features by applying the appropriate time delay to shift the peak of phase velocity spectrum to another mode's value. Fig. 2 shows phase velocity spectra for a four element comb transducer with a spacing of $6 \mathrm{~mm}$ at $750 \mathrm{kHz}$. Applying time delays creates a shift of the peak from a comb with no time delay as in Fig. 2 a). Consequently, the interference changes so that a new dominant mode is excited. 


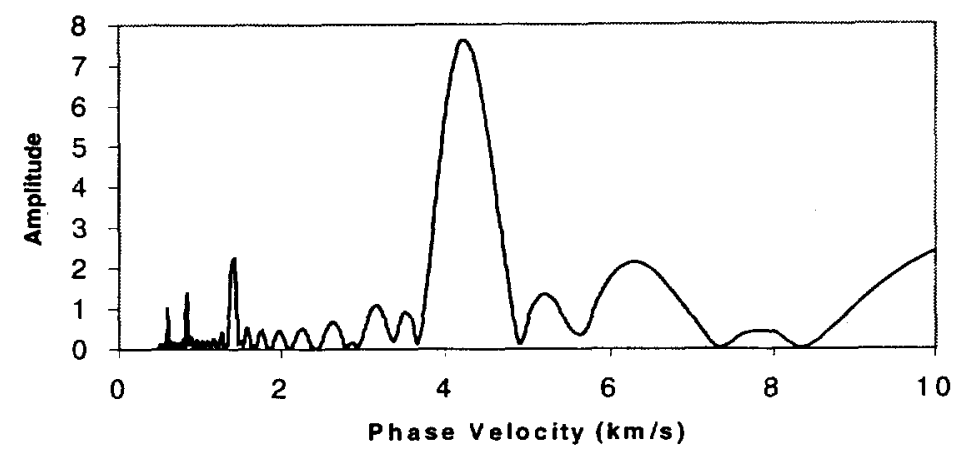

a) $\mathrm{td}=0$

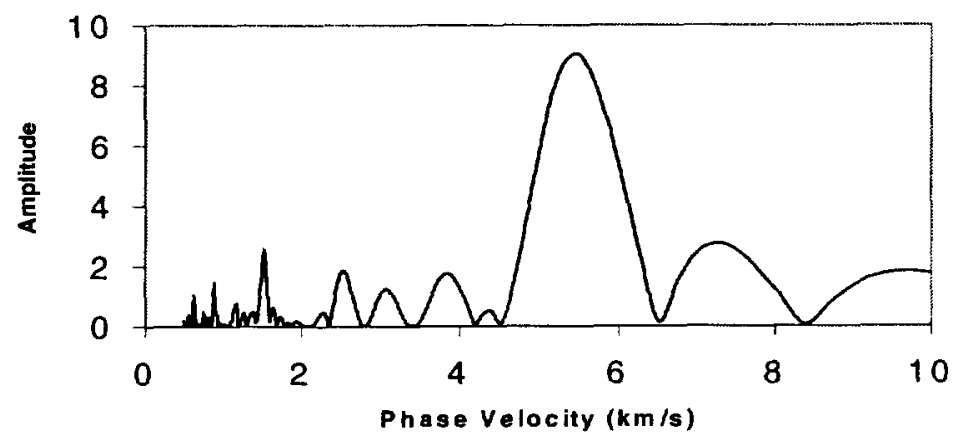

b) $\mathrm{td}=1.00 \mu \mathrm{s}$

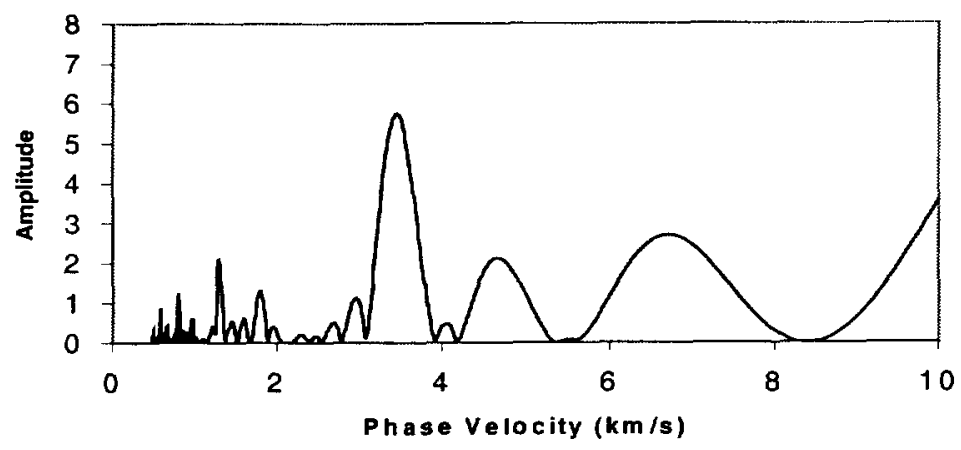

c) $\mathrm{td}=0.333 \mu \mathrm{s}$

FIGURE 2. Phase velocity spectra showing the shift of the peak for a four element comb transducer with a spacing of $6 \mathrm{~mm}$ at $750 \mathrm{kHz}$ and the time delay as shown.

Interference concepts can be used to determine the peaks and nulls of the spectrum, which correspond to constructive and destructive interference. Constructive interference in the forward propagating direction occurs when

$$
k s-\omega(t d)=2 q \pi
$$

where $\mathrm{q}=0,1,2, \ldots$ The backward propagation direction has constructive interference when 


$$
k s+\omega(t d)=2 q \pi
$$

Hence, the backward propagating direction has peaks that are different from the forward direction. Amplitude profiles across the comb transducer could be used to improve main lobe to side lobe ratios or to narrow the spectrum; however, the peak could not be shifted by an amplitude profile. The phase term is required to shift the peak of the phase velocity spectrum.

\section{EXPERIMENTAL RESULTS}

A four element comb transducer was driven with a tone-burst system with time-delay features to select and excite modes at a given frequency. An angle beam transducer was used to receive the excited modes. The angle of incidence of the receiver, which determines the phase velocity through Snell's Law, and the group velocity were used to verify the identity of the excited mode. Dispersion curves for a 3.5" O.D. steel pipe are shown if Fig. 3 and 4.

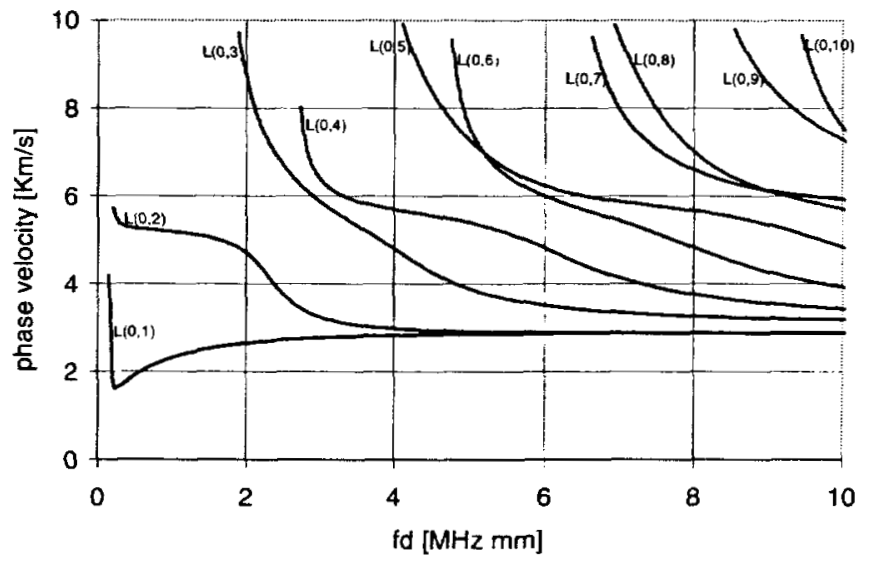

FIGURE 3. Phase velocity dispersion curves for a 3.5" O.D. steel pipe with a thickness of $5.5 \mathrm{~mm}$.

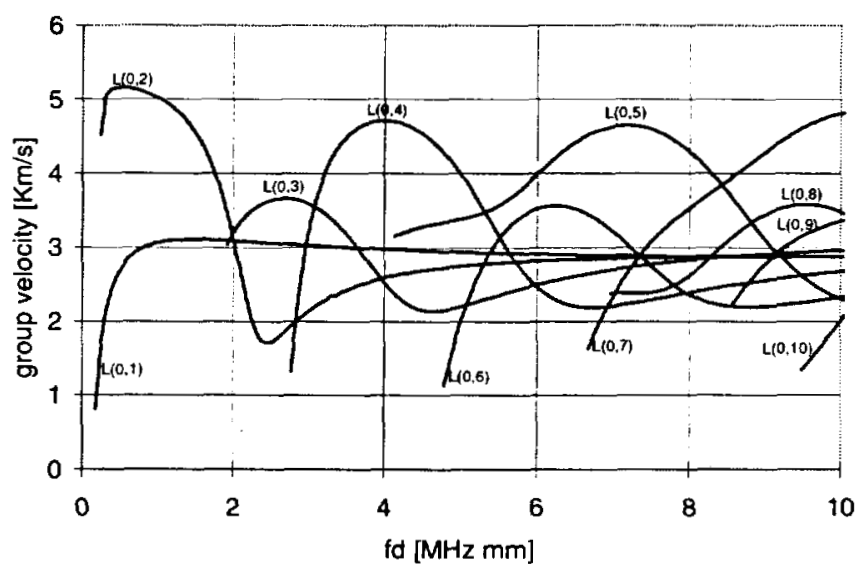

FIGURE 4. Group velocity dispersion curves for a 3.5" O.D. steel pipe with a thickness of $5.5 \mathrm{~mm}$. 
A four element comb with a spacing of $6 \mathrm{~mm}$ at $750 \mathrm{kHz}$ generates an $\mathrm{L}(0,3)$ mode with no time delay. A sample waveform is shown in Fig. 5. Time delays were estimated to generate $\mathrm{L}(0,4)$ and $\mathrm{L}(0,1)$ modes. Fig. 6 shows the generated waveform for an $\mathrm{L}(0,4)$ mode at $750 \mathrm{kHz}$ with a time delay of $1.00 \mu \mathrm{s}$. Each element has a time delay that is an integer multiple that is one less than the element number as shown in Table 1 . An $L(0,1)$ mode as well as an $\mathrm{L}(0,2)$ mode was generated with a time delay of $0.33 \mu$ s as shown in Fig. 7 . Two modes were generated, because they are so close together on the phase velocity dispersion curves at $4.1 \mathrm{MHz} \mathrm{mm}$.

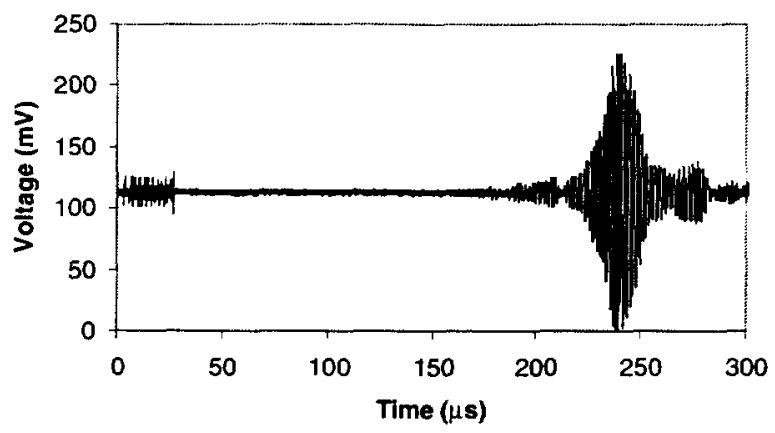

FIGURE 5. An RF waveform of an $\mathrm{L}(0,3)$ mode generated by a comb with no time delay at $750 \mathrm{kHz}$ and a spacing of $6 \mathrm{~mm}$. The receiving angle was 40 degrees.

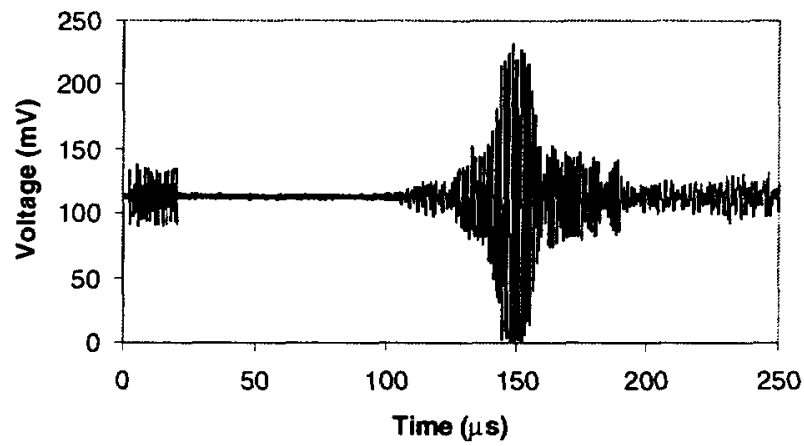

FIGURE 6. An RF waveform of an $\mathrm{L}(0,4)$ mode generated by a comb with a time delay of $1.00 \mu \mathrm{s}$ at $750 \mathrm{kHz}$ and a spacing of $6 \mathrm{~mm}$. The receiving angle was 28 degrees.

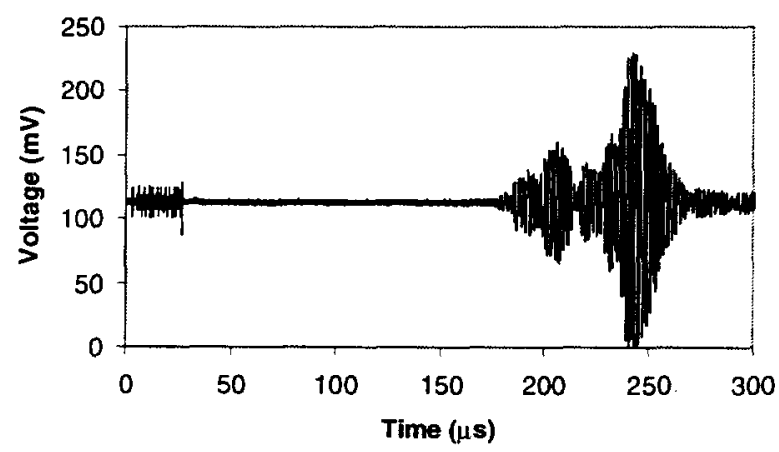

FIGURE 7. An RF waveform of an $L(0,1)$ and $L(0,2)$ modes generated by a comb with a time delay of $0.33 \mu$ s at $750 \mathrm{kHz}$ and a spacing of $6 \mathrm{~mm}$. $\mathrm{L}(0,1)$ is the faster mode as indicated by the group velocity dispersion curves. The receiving angle was 70 degrees. 
Group velocity was used to verify results. As can be seen in Fig. 4 at $\mathrm{fd}=4.1 \mathrm{MHz}$ $\mathrm{mm}, \mathrm{L}(0,4)$ has the highest group velocity and has the earliest arrival time. $L(0,1)$ is second fastest. The results show the potential of using a comb transducer with time delay features to select and excite many modes at a given frequency.

\section{CONCLUDING REMARKS}

A model for analyzing and understand the excitation of guided waves by a time delay comb transducer has been developed. Fundamental wave concepts are incorporated into the analysis to provide physical insight into the excitation by an arbitrary source. The method of analysis is applicable to any type of transduction mechanism, such as electromagnetic acoustic, piezoelectric, or magnetostrictive. Experimental results showed the excitation of several modes at a given frequency through time delay parameters. The results demonstrate that it is possible to perform mode tuning through the utilization of a comb transducer with time delay profiles.

\section{REFERENCES}

1. Alleyne, D.N., Cawley, P., Materials Evaluation, Vol. 45, No. 4, p. 504, (1997).

2. Quarry, M.J., Rose, J.L., Materials Evaluation, Vol. 57, pp.1089-1091 (1999).

3. Kwun, H., Holt, A.E., NDT\&E International, Vol. 28, p. 211, (1995).

4. Ditri, J.J., Rose, J.L, and Chen, G., Mode Selection Criteria for Defect Detection Optimization Using Lamb Waves, in Review of Progress in Quantitative Nondestructive Evaluation, Vol. 11, New York, 1992, pp. 2109-2115.

5. Chang, Z. and Mal, A.K., Mechanics of Materials, Vol. 31, pp. 197-204 (1999).

6. Datta, S.K., Al-Nassar, Y., Shah A.H., "Lamb Wave Scattering by a Surface Breaking Crack in a Plate," in Review of Progress in Quantitative Nondestructive Evaluation, Vol. 10, 1991, pp. 97-104.

7. Cho, Y., Hongerholt, D.D., and Rose, J.L., IEEE Transactions on Ultrasonics, Ferroelectrics, and Frequency Control, Vol. 44, No. 1, p.44 (1997).

8. Shin, H.J., Quarry, M.J., and Rose, J.L., "Non-axisymmetric Guided Waves for Tubing Inspection," in Review of Progress in Quantitative Nondestructive Evaluation, Vol. 15, 1996, pp. 1253-1260.

9. Auld, B.A., Acoustic Fields and Waves in Solids, Volume II, A Wiley-Interscience publication, New York, 1973.

10. Auld, B.A., Kino, G.S., IEEE Transactions on Electron Devices, Vol. ED-18, pp. 898-908 (1971).

11. Ditri, J.J. and Rose, J.L., Journal of Applied Physics, Vol. 72, No. 7, 2589-2597, (1992).

12. Viktorov, I.A., Rayleigh and Lamb Waves, Plenum Press, New York, 1967.

13. Rose, J.L., Pelts, S., Quarry, M.J., Ultrasonics, Vol. 36, p. 163-168, (1998).

*This work was performed under the auspices of the U.S. Department of Energy by University of California Lawrence Livermore National Laboratory under contract No. W-7405-Eng-48. 